\title{
PENGGUNAAN MEDIA RUMAH BELAJAR BERBASIS E-LEARNING DALAM MENINGKATKAN MOTIVASI BELAJAR PPKN SISWA KELAS XI TKJ
}

\author{
Aryani Lestari Putri ${ }^{1}$, Lina Marlina ${ }^{2}$ \\ Universitas Banten Jaya \\ Serang, Indonesia \\ narasenja06@gmail.com ${ }^{1}$, linamarlina@unbaja.ac.id ${ }^{2}$
}

\begin{abstract}
Education is a medium that has a major role in creating quality humans and providing various aspects of life. The development and progress of a country can be seen from how education can form quality Human Resources (HR). In this digital era, technology development is increasing rapidly. This happens because of the world of the Industrial Revolution 4.0 where technology is the fundamental thing in it. Workers in all fields in the era of the industrial revolution 4.0 are required to have digital skills, such as in the fields of development, economy and education. Various kinds of technology should be applied in preparing for classroom learning. One of the uses of technology in learning that makes this possible is the use of Information and Communication Technology (ICT). Where in reality that learning does not have difficulty in building by space and distance which is impossible if done naturally, but the expected reality can be realized through an innovation or renewal of the educational aspect through the concept of E-Learning. So that the use of existing or updated media is expected to be able to stimulate student motivation to be more interested in learning activities. This study aims to describe how the use of E-Learning-based Learning House media in increasing learning motivation for PPKn class XI TKJ students at SMK Negeri 1 Kragilan and to see what are the obstacles in using Rumah Belajar media and the efforts that can be made by teachers. in increasing student motivation.
\end{abstract}

Keywords: E-Learning, Home Learning, Student Learning Motivation

\section{PENDAHULUAN}

\begin{abstract}
Pendidikan merupakan media yang memiliki peran utama dalam
\end{abstract} menciptakan manusia yang berkualitas dan berpotensi dalam berbagai aspek kehidupan. Untuk menunjang proses kegiatan belajar mengajar seorang guru membutuhkan perangkat pembelajaran berupa Rencana Pelaksanaan Pembelajaran (RPP) dan Silabus. Disamping dari dua perangkat tersebut seorang guru pun membutuhkan media pembelajaran. Perkembangan dari awal sejarah pembelajaran, media hanyalah merupakan alat bantu yang dipergunakan oleh seorang guru untuk menerangkan pembelajaran. "Segala sesuatu yang dapat digunakan untuk menyalurkan pesan yang dapat merangsang pikiran, perasaan, perhatian dan kemauan siswa untuk belajar." (Miarso dalam R. Susilana \& C. Riyana, 2018:6). Maka media merupakan sebuah wadah dari pesan yang ingin disampaikan. Sedangkan pembelajaran memiliki arti yaitu "Pembelajaran merupakan suatu kegiatan yang melibatkan seseorang dalam upaya memperoleh pengetahuan, 
keterampilan, dan nilai-nilai positif dengan memanfaatkan berbagai sumber untuk belajar." (R. Susilana \& C. Riyana, 2018:1). Penggunaan media pembelajaran ini digunakan agar siswa lebih mudah untuk menerima materi yang ingin disampaikan oleh guru.

Pada era digital ini perkembangan teknologi semakin pesat. Hal ini dikarenakan dunia memasuki Revolusi Industri 4.0 dimana teknologi menjadi hal yang mendasar didalamnya. Tenaga kerja dalam semua bidang pada era revolusi industri 4.0 dituntut memiliki keterampilan digital, seperti dalam bidang pembangunan, ekonomi dan pendidikan. Berbagai macam teknologi sudah seharusnya diterapkan dalam pengajaran dikelas. Salah satu alternatif pemanfaatan teknologi dalam pembelajaran yang memungkinkan hal tersebut adalah dengan pemanfaatan Teknologi Infomasi dan Komunikasi (TIK). (BambangWarsita. 2019:66). Portal rumah belajar adalah portal yang dibangun oleh Kementerian Pendidikan dan Kebudayaan (KEMENDIKBUD) untuk memfasilitasi ketersediaan materi pembelajaran konten yang dapat dimanfaatkan oleh pendidik dan peserta didik, seperti materi pembelajaran interaktif yang dilengkapi dengan gambar media pendukung, animasi, video, dan simulasi. Dengan portal ini diharapkan proses belajar mengajar akan lebih banyak. (Bambang Warsita, 2019:68).

Rumah Belajar adalah program jaringan sekolah yang dikembangkan oleh Pustekkom yang berfungsi sebagai 1) wahana komunikasi lintas sekolah; 2) wadah sumber belajar; dan 3) wahana berbagi informasi antar sekolah di Indonesia. Sebagai portal pendidikan, edukasi dapat diakses oleh siapa saja dan kapan saja melalui url : http://belajar.kemdikbud.go.id Dengan tiga peran utama tersebut, maka Rumah belajar dapat berfungsi atau dikatakan pula sebagai jaringan sekolah (Schoolnet). (H. Yudiastuti. \& Megawanty, 2015:163).

Pemanfaatan internet sebagai media pembelajaran memiliki beberapa kelebihan, yaitu: Proses pembelajaran bisa terjadi di mana saja, Proses pembelajaran tidak terbatas oleh waktu, seperti halnya tatap muka, Pembelajaran dapat memilih topik atau bahan ajar yang sesuai dengan keinginan dan kebutuhan masing-masing, Lama waktu belajar juga tergantung pada kemampuan masing-masing pembelajar, dan Adanya keakuratan dan kekinian materi pembelajaran. (Sanjaya, 2010 dalam Aida Khairunnisa. Et al, 2015:2).

Pembelajaran yang bersifat konvensional atau tradisional semakin lama akan tergantikan. Dimana secara realitas bahwa pembelajaran itu tidak sulit 
walaupun dibatasi oleh ruang dan jarak yang tidak mungkin jika dilakukan secara alamiah, akan tetapi justru realitas yang diharapkan ini mampu diwujudkan melalui sebuah inovasi atau pembaharuan dari aspek pendidikan melalui konsep $E$ Learning. Pembelajaran campuran adalah pendekatan pembelajaran yang mengintegrasikan tatap muka tradisional pembelajaran dan pembelajaran jarak jauh menggunakan sumber belajar online dan berbagai pilihan komunikasi yang dapat digunakan guru dan Murid. Penerapan model pembelajaran ini memungkinkan penggunaan sumber belajar online,

terutama web- berdasarkan, tanpa meninggalkan aktivitas tatap muka. (A.D. Untari \& A. Millatussa'adiyyah, 2019:410).

Pelajar mandiri pada waktu tertentu dan bertanggung-jawab untuk pembelajarannya. Suasana pembelajaran E-Learning akan memaksa pelajar memainkan peranan yang lebih aktif dalam pembelajarannya. "E-Learning merupakan sebagai sebuah bentuk teknologi informasi yang di terapkan dibidang pendidikan dalam bentuk sekolah maya. " (Antonius A. Hartanto \& Ono W. Purbo, 2002:1). ELearning termasuk kedalam sebuah pembaharuan yang dapat dimanfaatkan dalam proses pembelajaran, tidak hanya dalam penyampaian materi pembelajaran tetapi juga perubahan dalam kemampuan berbagai kompetensi peserta didik. Berbagai pertimbangan melalui latar belakang dunia pendidikan yang semakin maju, para pengembang media pembelajaran memilih untuk menciptakan media yang mampu menarik perhatian siswa secara mandiri.

Studi yang dilakukan di Amerika sangat mendukung dikembangkannya $e$ learning, yakni menyatakan bahwa $e$ learning sangat efektif, memungkinkan $30 \%$ pendidikan lebih baik, $40 \%$ waktu lebih singkat, dan $30 \%$ biaya lebih murah. (Hamzah B. Uno, 2016:40). Dengan memperhatikan hal tersebut, peneliti mencoba untuk meneliti tentang penggunaan media Rumah Belajar berbasis E-Learning, yang dapat diakses menggunakan smartphone maupun laptop sebagai media pembelajaran elektronik ( $E$ Learning).

Sehingga dalam penggunaan media yang sudah ada maupun yang di perbaharui diharapkan mampu untuk merangsang motivasi belajar siswa agar lebih tertarik dalam kegiatan belajar. Motivasi meliputi proses yang di dalamnya terdapat energi, mengarahkan, dan mempertahankan perilaku. Selain itu, untuk mengetahui penggunaan media sudah tepat atau sesuai dengan materi yang ingin disampaikan oleh guru. "Motivasi merupakan stimulasi atau rangsangan agar perilaku terjadi sesuai dengan arahan yang 
dikehendaki." (Azwar, 2000 dalam N. Khodijah, 2014:151).

Peneliti menemukan beberapa permasalahan yang terjadi di lokasi penelitian yaitu di SMK Negeri 1 Kragilan salah satunya hasil dari pra penelitian yaitu penggunaan media pembelajaran yang di gunakan oleh guru apakah sudah dapat merangsang motivasi belajar siswa di kelas dalam mata pelajaran Pendidikan Pancasila dan Kewarganegaraan. Pada perkembangan zaman yang semakin maju dan sudah memasuki era Revolusi Industri 4.0 yang mengakibatkan banyak terjadinya pembaharuan-pembaharuan dalam segi teknologi dan berbagai aspek kehidupan. Salah satunya dalam bidang pendidikan, pemerintah telah membuat sebuah website dan aplikasi berbasis E-Learning untuk menunjang pembelajaran antara guru dan siswa, berupa Rumah Belajar berbasis $E$ Learning.

Dari pra penelitian di dapatkan bahwa guru mata pelajaran Pendidikan Pancasila dan Kewarganegaraan sudah menggunakan media pembelajaran berupa audio visual, visual, dan role playing yang dapat merangsang motivasi belajar siswa di kelas. Namun, seringkali guru masih menjadi pusat pembelajaran di kelas dan mata pelajaran Pendidikan Pancasila dan Kewarganegaraan seringkali dianggap sebagai mata pelajaran yang kurang menarik dibandingkan mata pelajaran lainnya yang mengakibatkan motivasi belajar siswa pada pembelajaran Pendidikan Pancasila dan Kewarganegaraan di sekolah belum meningkat. Di lokasi penelitian yaitu di SMK Negeri 1 Kragilan sudah menggunakan kurikulum tigabelas, dimana siswa-siswi di haruskan untuk lebih mandiri dalam proses pembelajaran yaitu ketika siswa-siswi mencari materi pembelajaran dan menjawab permasalahan atau pertanyaan yang di berikan oleh guru, karena guru hanya berperan sebagai fasilitator. Sebelum terjadinya masa pandemi Covid-19 guru mata pelajaran Pendidikan Pancasila dan Kewarganegaraan SMK Negeri 1 Kragilan memberikan materi pembelajaran di dalam kelas dengan menggunakan media power point dan menggunakan model pembelajaran diskusi agar siswa-siswi dapat aktif dalam proses pembelajaran. Sedangkan dikondisi saat ini ketika masa pandemi Covid-19 guru mata pelajaran Pendidikan Pancasila dan Kewarganegaraan SMK Negeri 1 Kragilan dapat dilihat bahwa proses pembelajaran sudah berpindah tidak di sekolah atau di dalam kelas, melainkan di rumah masingmasing dari siswa-siswi kelas XI TKJ, untuk model pembelajaran yang digunakan pun yaitu model pembelajaran E-Learning dengan media yang digunakan yaitu Rumah Belajar. Dengan menggunakan 
Rumah Belajar berbasis E-Learning yang di dalamnya terdapat berbagai macam layanan atau fitur untuk menunjang guru dan siswa dalam proses pembelajaran serta memberikan rangsangan motivasi belajar siswa agar lebih antusias dalam proses pembelajaran. Sehingga mampu memberikan hasil belajar siswa yang sesuai dengan tujuan pembelajaran yang sudah ada.

Kehadiran Portal Rumah Belajar di dunia maya (internet) menambah khasanah sumber belajar bagi dunia pendidikan di Indonesia. Portal Rumah Belajar ini memudahkan guru membuat pembelajaran menjadi lebih menarik, karena tersedia berbagai komponen yang diperlukan untuk pembelajaran, baik di kelas maupun di luar kelas, terutama penugasan kepada peserta didik agar peserta didik sedini mungkin mengenal teknologi. (Warsinah, 2012 dalam Bambang Warsita, 2019:67).

\section{METODE PENELITIAN}

Penelitian ini dilaksanakan di SMK Negeri 1 Kragilan. Adapun waktu penelitian akan dilaksanaka pada tanggal 4 Mei 2020 sampai dengan 6 Juni 2020 . Informan yang diteliti dalam penelitian ini yaitu Guru Mata Pelajaran Pendidikan Pancasila dan Kewarganegaraan SMK Negeri 1 Kragilan, Siswa kelas XI TKJ, Orangtua siswa. Pendekatan yang digunakan dalam penelitian ini adalah pendekatan kualitatif dengan menggunakan metode observasi, wawancara dan dokumentasi, menurut Bog dan Tylor, metode kualitatif adalah "prosedur penelitian yang menghasilkan data dekskriptif, yang berupa kata-kata tertulis atau lisan dari orang-orang dan perilaku yang diamati" (Moloeng, 2014:4). Artinya data yang dikumpulkan bukan berupa angka-angka, melainkan data tersebut berasal dari naskah wawancara, catatan lapangan, dokumen pribadi, catatan memo, dan dokumen resmi lainnya dan dideskripsikan dalam bentuk narasi. Dokumentasi dalam penelitian ini yaitu dengan mengumpulkan data melalui dokumen-dokumen yang berkaitan dengan penelitian seperti arsip, buku-buku, gambar-gambar yang berkaitan dengan penelitian.

\section{HASIL PENELITIAN DAN PEMBAHASAN}

Berdasarkan data hasil temuan dan analisis data dalam penelitian ini, maka peneliti akan membahas mengenai bagaimana penggunaan media Rumah Belajar berbasis E-Learning dalam meningkatkan motivasi belajar PPKn siswa kelas XI TKJ, hambatan apa saja yang di hadapi oleh gur dan siswa dalam penggunaan media Rumah Belajar berbasis E-Learning dalam meningkatkan motivasi belajar PPKn siswa kelas XI TKJ, upaya 
apa saja yang dapat dilakukan guru dalam penggunaan media Rumah Belajar berbasis E-Learning dalam meningkatkan motivasi belajar PPKn siswa kelas XI TKJ. Sesuai dengan hasil penelitian diatas, pembahasan hasil penelitian tentang Penggunaan Media Rumah Belajar Berbasis E-Learning dalam Meningkatkan Motivasi Belajar PPKn Siswa Kelas XI TKJ di SMK Negeri 1 Kragilan diperoleh berdasarkan hasil observasi, wawancara, dan dokumentasi. Selanjutnya dapat dijabarkan sebagai berikut :

1. Bagaimana Penggunaan Media Rumah Belajar Berbasis $E$ Learning dalam Meningkatkan Motivasi Belajar PPKn Siswa Kelas XI TKJ di SMK Negeri 1 Kragilan

Berdasarkan hasil penelitian dalam penggunaannya sudah sangat membantu bagi guru maupun siswa. Media Rumah Belajar ini mudah diakses dan membantu bagi guru dalam mendapatkan dan membandingkan sumber belajar, guru belajar hal yang baru, guru dapat berinteraksi dengan guru lainnya dan guru bisa membuat video pembelajaran yang kreatif sesuai dengan materi pembelajaran yang disampaikan, sedangkan bagi siswa memudahkan siswa dalam mencari sumber belajar lainnya serta fitur atau layanan yang di sajikan tidak membuat bosan siswa.

2. Bagaimana hambatan yang di hadapi oleh guru dan siswa dalam Penggunaan Media Rumah Belajar Berbasis E-Learning dalam Meningkatkan Motivasi Belajar PPKN Siswa Kelas XI TKJ di SMK Negeri 1 Kragilan

Berdasarkan hasil wawancara, hambatan-hambatan yang dialami oleh guru, siswa dan orangtua siswa dalam penggunaan media Rumah Belajar berbasis E-Learning dalam meningkatkan motivasi belajar PPKn siswa, menurut data dari hasil penelitian menyatakan sebagai berikut : Pertama, Faktor Perangkat Siswa yaitu tidak semua siswa memiliki fasilitas laptop secara pribadi, sedangkan laptop dan komputer yang disediakan oleh sekolah jumlahnya masih kurang dan penggunaannya pun harus bergantian dengan kelas lain. Selain itu koneksi jaringan internet dan keterbatasan paket internet yang dimiliki siswa, tidak semuanya mampu dapat mengakses Rumah Belajar, dan wifi yang disediakan oleh sekolah pun terkadang kurang mendukung. Kedua, Faktor Ekonomi yaitu tidak semua orangtua siswa berasal dari kelas sosial menengah ke atas, namun 
beberapa diantaranya juga berasal dari kelas sosial menengah ke bawah yang mengakibatkan tidak semua siswa mampu memiliki fasilitas berupa laptop dan smartphone. Ketiga, Faktor Tenaga Pendidik dan Lingkungan Kelas yaitu cara mengajar guru di dalam kelas pun menjadi faktor dalam perkembangan motivasi belajar siswa. Seringkali cara mengajar guru yang menggunakan metode ceramah membuat siswa menjadi merasa jenuh didalam kelas sehingga daya serap pelajaran pun tidak sesuai dengan tujuan pembelajaran. Selain itu faktor lingkungan kelas berpengaruh bagi perkembangan motivasi belaja siswa, pengaruh dari teman kelas yang memiliki semangat rendah atau motivasi rendah dalam belajar akan mempengaruhi teman lainnya. Begitu pun sebaliknya jika teman kelas memiliki semangat tinggi atau motivasi tinggi dalam belajar akan berpengaruh dalam hasil akhir siswa atau hasil penilaian siswa baik secara kognitif, afektif dan psikomotorik.

3. Bagaimana hambatan yang di hadapi oleh guru dan siswa dalam Penggunaan Media Rumah Belajar Berbasis $E$ Learning dalam Meningkatkan Motivasi BelajarPPKN Siswa

\section{Kelas XI TKJ di SMK Negeri 1 Kragilan}

Berdasarkan hasil wawancara, upaya-upaya yang dapat dilakukan dalam penggunaan media Rumah Belajar berbasis E-Learning dalam meningkatkan motivasi belajar PPKn siswa, menurut data dari hasil penelitian menyatakan sebagai berikut, yaitu guru bisa membuat video pembelajaran yang kreatiftayangan video yang kreatif dan bisa ditonton berulang itulah yang coba guru tekankan kepada siswa sehingga dengan itu siswa akan mudah termotivasi dalam belajar. Sedangkan untuk motivasi belajar siswa, guru mempelajari karakter siswa kemudian melakukan pendekatan secara persuasif sehingga dapat dilakukan pemberian motivasi yang tepat dan pemberian motivasi kepada siswa, guru pun berupaya memberikan apersepsi dan pemberian motivasi yang diterapkan di awal sebelum pembelajaran di mulai.

\section{KESIMPULAN}

Berdasarkan penelitian dapat ditarik kesimpulan bahwa penggunaan media Rumah Belajar berbasis E-Learning dalam meningkatkan motivasi belajar PPKn 
siswa kelas XI TKJ di SMK Negeri 1 Kragilan, yaitu sangat membantu bagi guru dan siswa-siswi. Serta dapat memotivasi belajar PPKn siswa-siswi. Kesimpulan berdasarkan dari rumusan masalah pertama yaitu penggunaan media Rumah Belajar berbasis E-Learning dalam meningkatkan motivasi belajar PPKn siswa kelas XI TKJ di SMK Negeri 1 Kragilan, sangat membantu bagi guru dan siswa-siswi. Karena, bagi guru lebih banyak mendapatkan perbandingan sumber belajar, guru pun dapat belajar hal yang baru dan guru dapat berinteraksi dengan guru lainnya. Sedangkan untuk siswa sangat membantu dalam mencari sumber belajar dan memahami materi pembelajaran. Media Rumah Belajar berbasis E-Learning sangat mudah diakses dan fitur medianya variatif sehingga tidak membuat siswa menjadi bosan dalam belajar. Guru dapat membuat video pembelajaran yang kreatif sesuai dengan materi yang di sampaikan, tayangan video yang kreatif dan bisa ditonton berulang itulah yang guru tekankan kepada siswa sehingga dengan itu siswa akan mudah termotivasi dalam belajar. Sedangkan motivasi belajar siswa dapat dilihat dari hasil penilaian guru terhadap siswa, terdapat pula faktor-faktor yang mempengaruhi motivasi belajar siswa yaitu keterlibatan guru dalam mengajar dan keterlibatan teman kelas atau lingkungan belajar berpengaruh dalam motivasi belajar siswa, dan untuk cara mendidik orangtua kepada anak pun dapat berpengaruh bagi motivasi belajar siswa. Berdasakan kesimpulan dari rumusan masalah kedua yaitu dalam penggunaannya terdapat pula hambatan yang di hadapi guru dan siswa dalam menggunakan media Rumah Belajar untuk meningkatkan motivasi belajar PPKn siswa, yaitu hambatan yang dialami ketika penggunaan media Rumah Belajar pada perangkat siswa dan koneksi jaringan serta paket internet yang dimiliki siswa, serta adapula faktor yang menyebabkan motivasi siswa menjadi meningkat atau tidaknya yaitu dari dalam diri siswa itu sendiri, keterlibatan guru dalam proses pembelajarandan proses mendidik siswa menjadi meningkat atau tidaknya motivasi belajar siswa, keterlibatan pengaruh teman atau lingkungan kelas pun menjadi faktor meningkat atau tidaknya motivasi belajar siswa. Berdasarkan kesimpulan dari rumusan masalah ketiga yaitu adanya hambatan-hambatan yang dirasakan baik dari guru, siswa dan orangtua maka perlu diadakan sebuah upaya-upaya yang dapat dilakukan guru mengenai penggunaan media Rumah Belajar berbasis E-Learning dalam meningkatkan motivasi belajar PPKn siswa, yaitu dengan cara guru bisa membuat video pembelajaran yang kreatif, tayangan video yang kreatif dan bisa 
ditonton berulang itulah yang guru tekankan kepada siswa sehingga dengan itu siswa akan mudah termotivasi dalam belajar serta guru melakukan apersepsi dan pemberian motivasi kepada siswa-siswi sebelum memasuki pelajaran, menyanyikan lagu nasional agar semangat nasionalisme siswa-siswi dapat tumbuh, membicarakan hal-hal atau peristiwa yang sedang hangat di masyarakat agar siswasiswi dapat terangsang dari segi berpikir dan dapat memberikan pendapatnya. Selain dari guru, orangtua siswa pun memiliki peran yang penting dalam meningkatkan motivasi belajar siswa di sekolah yaitu dengan cara pemberian nasihat-nasihat dan dukungan yang positif kepada anak, agar anak tetap memiliki motivasi dalam bersekolah.

\section{DAFTAR PUSTAKA}

A.D. Untari \& A.

Millatussa'adiyyah (2019).

Implementation of Blended

Learning Through Google

Classroom in Generation $Z$. 410:162.

A Hartanto. Antonius \& Ono W. Purbo 2002. Buku Pintar Teknologi eLearning Berbasis PHP dan MySQL. Jakarta : PT Efexmedia Komputindo.
B, Uno Hamzah. 2011. Model

Pembelajaran Menciptakan Proses

Belajar Mengajar yang Kreatif dan Efektif (Edisi 1). Jakarta : Bumi Aksara.

Bambang Warsita (2019).Pemanfaatan Rumah Belajar Untuk Meningkatkan Kualitas Pembelajaran. Jurnal Teknodik. 23:66.

Helda, Y. \& Megawaty (2015). Mengukur Kualitas Portal Rumah Belajar dengan Menggunakan Metode Webqual 4.0. 17:163.

Khodijah Nyanyu. 2014. Psikologi Pemanfaatan Portal Rumah Pendidikan. Jakarta : PT Grafindo Belajar untuk Meningkatkan Persada. Kualitas Pembelajaran. 23:67.

Susilana, R \& Riyana, C. 2007.Media Pembelajaran. Bandung : CV Wacana Prima.

Warsinah (2012) dalamjurnal Bambang Warsita. 2019. 